\title{
A CONTRIBUIÇÃO DA PERCEPÇÃO DO PRODUCT PLACEMENT NA ATITUDE FRENTE ÀS MARCAS: UM ESTUDO NA SÉRIE HOUSE OF CARDS DA NE- TFLIX
}

NÍCOLAS MARQUES FERNANDES PAIVA UNIVERSIDADE FEDERAL DO CEARÁ FORTALEZA, CEARÁ, BRASIL E-MAIL: NICOLASMPAIVA@GMAIL.COM

ALINE RIBEIRO GOMES UNIVERSIDADE FEDERAL DO CEARÁ FORTALEZA, CEARÁ, BRASIL E-MAIL: ALINEARG@GMAIL.COM

YARA DE ALMEIDA BARRETO UNIVERSIDADE FEDERAL DO CEARÁ FORTALEZA, CEARÁ, BRASIL E-MAIL: YARABARRE@GMAIL.COM

HUGO OSVALDO ACOSTA REINADO UNIVERSIDADE FEDERAL DO CEARÁ FORTALEZA, CEARÁ, BRASIL E-MAIL: HUGO@UFC.BR 
A CONTRIBUIÇÃO DA PERCEPÇÃO DO PRODUCT PLACEMENT NA ATITUDE FRENTE ÀS MARCAS: UM ESTUDO NA SÉRIE HOUSE OF CARDS DA NETFLIX.

Resumo: O objeto de estudo do presente trabalho busca identificar a eficiência do Product Placement (PP). Realizou-se uma pesquisa qualitativa de caráter exploratório junto a audiência da série House Of Cards, que percebeu a presença de marcas e não se mostrou incomodada com o uso desse tipo de publicidade.

Palavras-chave: Eficiência; Marcas; Product Placement.

\section{LA CONTRIBUCIÓN DE LA PERCEPCIÓN DEL PRODUCT PLACEMENT EN LA ACTITUD HACIA LAS MARCAS: UN ESTUDIO DE LA SERIE DE LA NETFLIX, HOUSE OF CARDS.}

Resumen: El objeto de este estudio buscó determinar la eficacia del Product Placement (PP). Por lo tanto, una investigación cualitativa y exploratoria se aplicó con la audiencia de la serie House Of Cards, que se dio cuenta de la presencia de algunas marcas, y no se muestra para ser molestado por el uso de este tipo de publicidad.

Palabras clave: Eficiencia; Marcas; Product Placement.

THE CONTRIBUTION OF THE PERCEPTION OF PRODUCT PLACEMENT IN THE ATTITUDE TOWARDS BRANDS: A STUDY IN THE NETFLIX'S SERIES HOUSE OF CARDS.

Abstract: The object of this study sought to identify the efficiency regarding Product Placement (PP). Therefore, a qualitative and exploratory research was applied with the House Of Cards series' audience, which noticed the presence of some brands, and did not shown to be bothered about the using of this type of advertising.

Keywords: Efficiency; Brands; Product Placement. 


\section{INTRODUÇÃO}

O avanço na democratização das mídias digitais nesta segunda década do século XXI vem gerando profundas mudanças comportamentais na forma como as pessoas se comunicam e na sua relação com as empresas, Tal fato faz com que os setores de mídia busquem formas criativas, vanguardistas e atraentes para veicular suas marcas, produtos e/ou serviços. Para Tamanaha (2006), Lee e Faber (2007) e Jenkins (2009) a forma dos indivíduos se conectarem, ao mesmo tempo, às diferentes mídias influencia na sua maneira de consumir conteúdo.

Kotler e Keller (2012) afirmam que diariamente mais de 1.500 mensagens publicitárias são transmitidas aos indivíduos e a grande maioria dessas é filtrada e não chama a atenção dos mesmos. Devido a isso, o desafio dos profissionais de Marketing é saber quais estímulos serão percebidos. Quanto mais saturado de publicidade o mercado estiver, mais atento o consumidor estará e menos irão deixar-se envolver pelas formas de persuasão dos anunciantes (KOTLER; KELLER, 2012; LINDSTROM, 2009).

As evoluções tecnológicas, como a televisão por assinatura, os sistemas de pay per view e o conteúdo via streaming (Netflix e Apple TV) vêm pressionando as emissoras de televisão com relação à forma de consumir seu conteúdo e ao modo de lidar com seus comerciais tradicionais. Um estudo realizado pela Neilsen (2005), apontou o crescimento de diferentes tipos de métodos eletrônicos utilizados para evitar os blocos destinados à publicidade, em particular o uso de DVRs (gravadores de vídeo digital). Por meio destes gravadores, os telespectadores podem suprimir totalmente os intervalos comerciais (skipping) ou podem acelerá-los muito rapidamente (zipping) (LEHU, 2007).

É possível observar que mudanças como a maior conscientização dos telespectadores e o tempo escasso destinado à retenção de informações alteram consideravelmente o ambiente da comunicação, principalmente nas mídias de massa. Dessa forma, surge o interesse em buscar novas estratégias para despertar o interesse dos consumidores, como, por exemplo, o Product Placement (PP), tema deste estudo. Pelo fato desta ser uma técnica mais vanguardista, quando comparada aos tradicionais blocos comerciais, surgem questionamentos acerca da eficiência desse tipo de inserção entre os consumidores.

Este estudo tem como objetivo analisar a contribuição da percepção

Rev.Cad. Comun. Santa Maria, v.21, n.1, art 10, p.197 de 215, jan/abr.2017 
do PP na atitude dos telespectadores frente às marcas. Assim, constituem-se em objetivos específicos: identificar a lembrança espontânea das marcas, a lembrança estimulada pela categoria de produtos e a lembrança estimulada pela marca, e observar se ocorreu mudança de atitude após a exposição.

Para tanto, foi realizado um Estudo de Caso composto por duas fases: (1) exploratória, que compreendeu a seleção e a análise da oferta de conteúdo para identificar ações de PP realizadas numa série de grande penetração veiculada via streaming; (2) descritiva, onde ocorreu a aplicação de questionário junto à amostra obtida entre os que assistem à série, objeto desse estudo.

A análise dos dados coletados por meio das entrevistas revelou se a amostra estudada percebeu a inserção de marcas na série House of Cards e, por conseguinte, como se manifestaram as suas atitudes perante as mesmas, seja por meio de lembrança, simpatia, recomendação, intenção de compra.

\section{PRODUCT PLACEMENT}

Segundo Lehu (2007), Product Placement (PP) ou Brand Placement é a inserção não invasiva de marca, produto e/ou serviço em um conteúdo de entretenimento. Na televisão esse tipo de publicidade diverge dos blocos comerciais tradicionais, pois encontra-se inserida no conteúdo apresentado, alinhando-se com a receptividade do telespectador, e impedindo o desvencilhamento da audiência, principal vantagem dessa abordagem para os anunciantes.

O PP é uma técnica antiga, inicialmente associada ao cinema. De acordo com Newell, Salmon e Chang (2006), a primeira inserção de marca aconteceu em 1896, no filme "Washing Day in Switzerland". Conforme Andriasova (2006), uma das mais famosas aplicações de PP ocorreu com a marca de chocolate Hershey's no filme "E.T. O Extraterrestre", de 1982. Tal publicidade obteve um sucesso estrondoso, fazendo com que suas vendas triplicassem. Após essa inserção, passou a ser perceptível a sua utilização em grandes filmes, como a inserção da marca Pepsi em "De Volta Para o Futuro", de 1989, e dos óculos Ray-Ban no filme "Homens de Preto", de 1997 (ANDRIASOVA, 2006).

Rev.Cad. Comun. Santa Maria, v.21, n.1, art 10, p.198 de 215, jan/abr.2017 


\subsection{CATEGORIAS DO PRODUCT PLACEMENT}

O Product Placement pode ser categorizado por: (1) Modo - Visual Sonoro e/ou Audiovisual; (2) Proeminência - Proeminente ou Sutil; (3) Congruência (integração com a narrativa) - Alta, Média ou Baixa; (4) Uso de Personagens - Sim ou Não.

Blessa (2006, apud Lawall, 2013) subdivide a categoria Modo em outras três subcategorias, são elas: (1) Screen Placement - se resume a uma aparição visual; (2) Script Placement - inserido na fala do personagem; (3) Plot Placement - integrado na narrativa. Para Lehu (2007) o PP é dividido em quatro categorias, levando em consideração o seu grau de proeminência, de congruência e de uso dos personagens:

a) Product Placement Clássico: inserção simples e de fácil colocação. Apesar de não ser tão sofisticada, pode passar despercebida, principalmente se existir um grande número de inserções;

b) Coorporativo: prioriza a marca ao invés do produto. É arriscado, pois caso a audiência não conheça a marca, esta pode passar despercebida. O ponto positivo desse tipo de PP é a sua durabilidade, além disso, uma percepção de marca eficaz pode trazer benefícios a todos os produtos e serviços da mesma;

c) Evocativo: inserção discreta, feita sem a explicitação de marca. Pode não ser identificada, caso o público não seja familiarizado com a mesma. Devido a isto, é essencial ter um produto que seja original e com um design suficientemente distinto para evocar o nome da marca na mente do espectador;

d) Encoberto: forma mais discreta e indetectável de PP. Muitas vezes é bem integrado na cena e a sua presença discreta lhe dá um aspecto natural, o que pode gerar um impacto mais poderoso quando é identificado pela audiência.

Com relação ao uso de personagens, o carisma intrínseco a este pode ser transferido para as marcas e produtos que o mesmo utiliza em cena. Lehu (2007) aponta a existência de um princípio clássico de identificação 
e o desejo de se parecer, em diferentes níveis, com uma celebridade. Devido a isto, uma parte significativa do público está frequentemente desejando consumir as mesmas marcas e produtos utilizados pelo personagem em questão.

Outro ponto importante relacionado ao uso de PP diz respeito a uma maior tolerância por parte do público com este tipo de publicidade, quando comparada aos tradicionais blocos comerciais. Tal realidade faz com que os anunciantes invistam cada vez mais neste tipo de abordagem, potencializando seu uso (LEHU, 2007)

Para que o Product Placement cumpra seu papel, este deve ser percebido e gerar alguma atitude na audiência, tópicos que serão detalhados a seguir.

\section{PERCEPÇÃo}

Para Robbins (2005), Urdan e Urdan (2010) e Kotler e Keller (2012), a percepção pode ser definida como o processo pelo qual os indivíduos selecionam, organizam e interpretam as informações recebidas, alterando seu comportamento. Hawkins, Mothersbaugh e Best (2007) afirmam que a percepção se inicia com a exposição do consumidor aos estímulos de comunicação e é finalizada com a sua interpretação dos mesmos.

A percepção de um indivíduo difere de acordo a relação entre ele e o objeto. Conforme Robbins (2005) e Urdan e Urdan (2010), o conhecimento sobre um determinado objeto, a motivação do indivíduo, a sua personalidade, suas experiências, seus valores e estilo de vida, são fatores que diferenciam a maneira que algo pode ser percebido, levando a percepções distintas e, consequentemente, a comportamentos diferenciados. Kotler e Keller (2012) afirmam que as diferentes percepções acerca de um mesmo objeto ocorrem devido a três processos: atenção seletiva, distorção seletiva e retenção seletiva. Neste artigo, percepção relaciona-se com atenção seletiva, onde os indivíduos respondem predominantemente aos estímulos que lhes são significativos, filtrando apenas aquelas mensagens que lhes agregam uma maior significância.

Devido a isto, apesar da grande quantidade de mensagens que são transmitidas diariamente, os indivíduos tendem a prestar atenção somente a um número bastante reduzido. Lehu (2007) considera um feito o tipo de inserção que consegue facilitar a introdução e a preservação 
de uma marca na mente dos consumidores. Para o autor, a familiaridade com a marca e a sua frequência de consumo, são pontos importantes que facilitam a memorização.

Saindo da esfera da percepção individual e migrando para o âmbito geral, é possível encontrar grupos de pessoas que recebam os mesmos estímulos e elaborem percepções e interpretações similares, resultando em comportamentos semelhantes. Assim, o conceito de segmentação contribui para a efetividade das comunicações.

\section{SEGMENTAÇÃo DE MERCADO}

O estudo de segmentação de mercado iniciou-se a partir do empenho das organizações em oferecer produtos que atendessem às necessidades de um mercado específico, contrapondo-se ao mercado de massa que, segundo Kotler e Keller (2012), se apoia em um único mercado, obtendo baixos custos de produção e, consequentemente, preços baixos ou margens altas. Contudo, o que se percebe, cada vez mais é a fragmentação do mercado, tornando-o mais homogêneo para atendê-lo de forma mais eficiente (ETZEL; WALKER; STANTON, 2001).

Para Kotler e Armstrong (2007) as principais variáveis de segmentação de mercados consumidores são: geográficas (unidades geográficas), demográficas (sexo, idade, tamanho da família, renda e ocupação), psicográficas (classe social, estilo de vida ou características da personalidade) e comportamentais (conhecimento, atitudes, uso e reações).

Entre as formas de segmentação apontadas, a psicográfica tem maior proximidade ao público da pesquisa, pois no mercado de entretenimento, Saraiva Júnior (2008) explica que o público-alvo escolhe suas atividades de lazer e desenvolve seu estilo de lazer em virtude da proximidade com outras pessoas e em um contexto específico, ou seja, de acordo com seu estilo de vida.

O consumo de entretenimento também conta com a segmentação para atingir o maior número de consumidores e patrocinadores possíveis. Por isso, deve-se alertar ao fato da ampliação das ofertas de programas de lazer, onde o espectador decide o que ver e quando (COBRA, 2008). Logo, Vogelstein (2014) explica que o entretenimento é acessado de maneiras completamente novas, como é o caso do conteúdo streaming da Netflix.

Por isso, ao perceber que as empresas se utilizam da segmentação

Rev.Cad. Comun. Santa Maria, v.21, n.1, art 10, p.201 de 215, jan/abr.2017 
para destinar o conteúdo certo ao consumidor de acordo com seu comportamento, o presente estudo procurou compreender como a atitude é definida e formada, a fim de observar a influência do Product Placement na atitude de um determinado público alvo.

\section{ATITUDE}

Mowen e Minor (2001), Pinheiro et al (2006), Thurstone (1976) e Katz (1960) definem a atitude como a extensão da afeição ou sentimento despertado positivamente ou negativamente em relação a um estímulo ou objeto. Ela também é um arranjo construído ao longo do tempo a partir dos processos motivacionais, emocionais, perceptivos e cognitivos referentes a alguma particularidade de determinado ambiente (HAWKINS; MONTHERSBAUGH; BEST, 2007).

Conforme Pinheiro et al (2006, p. 28), "as atitudes têm o poder de orientar e guiar o nosso comportamento". Após sua consolidação, a mudança das atitudes apresenta-se como um processo complexo, uma vez que exige uma abrangente reorganização do sistema de crenças e valores dos indivíduos (KOTLER; ARMSTRONG, 2007; PINHEIRO ET AL, 2006).

Hawkins, Monthersbaugh e Best (2007), bem como Mowen e Minor (2001) e Katz (1960) elucidam as quatro funções principais das atitudes nos indivíduos:

a) Funçãodeconhecimento-aatitudesebaseiana crença préviado consumidor perante os objetos ou atividades, marcas e compras;

b) Função de expressão de valor - nesse quesito as atitudes expressam os valores centrais e a autoimagem do indivíduo;

c) Função utilitária - a atitude em face aos objetos e atividades é definida pela existência ou inexistência de uma recompensa. A resposta será favorável caso ocorra compensação e desfavorável quando esta inexistir;

d) Função de defesa do ego - as atitudes são utilizadas na defesa do ego e da autoimagem diante das ameaças e falhas que possam ocorrer.

A atitude de um consumidor perante diferentes marcas, conforme Rev.Cad. Comun. Santa Maria, v.21, n.1, art 10, p.202 de 215, jan/abr.2017 
Kotler e Armstrong (2007), é estabelecida através de alguns processos avaliatórios que levam em conta as características pessoais do consumidor, bem como a situação na qual se encontram, além das influências das pessoas que o cercam.

Assim como na percepção, o claro discernimento dos elementos formadores das atitudes do consumidor afeta direta ou indiretamente as decisões de Marketing, permitindo decisões mais acertadas na utilização de meios alternativos de publicidade, como o Product Placement. Dessa forma, empresas como a Netflix, que se utilizam do PP, necessitam do estudo das atitudes de seus consumidores com o propósito de provocar resultados positivos do público-alvo dos seus anunciantes em relação aos seus produtos.

\section{NETFLIX E HOUSE OF CARDS}

A Netflix é uma empresa norte-americana de serviço de entretenimento. Fundada em 29 de agosto de 1997, por Reed Hastings e Marc Randolph, nos Estados Unidos, começou a operar oficialmente no dia 14 de abril de 1998 (GINA KEATING, 2013) como uma locadora virtual onde os filmes e/ou seriados eram escolhidos e alugados no site da empresa e entregues em casa, sem a necessidade de deslocamento e existência de multa.

Em 2007 a Netflix introduziu na empresa o serviço streaming - transmissão instantânea de vídeos pela internet - possibilitando que seus assinantes assistissem todo o seu catálogo de filmes e séries na tela do computador (NETFLIX MEDIA CENTER, 2016).

Apesar da empresa de serviços de streaming de vídeos não divulgar oficialmente dados acerca de sua audiência, uma pesquisa de banco de dados realizada entre os assinantes do serviço nos EUA e divulgada por Wallensteing (2015) informou que em março desse ano a terceira temporada de House Of Cards atraiu 6,5\% dos telespectadores nos primeiros 30 dias de exibição, indicando que cerca de 2.65 milhões de telespectadores norte-americanos assistiram pelo menos um episódio da terceira temporada da série, nos trinta primeiros dias em que esta ficou disponível.

House Of Cards foi a série que inaugurou a produção de conteúdo original da Netflix. É um drama político que gira em torno de Frank Underwood (Kevin Spacey), um congressista norte-americano ambicioso e manipulador, que juntamente com a sua esposa, Claire (Robin Wright),

Rev.Cad. Comun. Santa Maria, v.21, n.1, art 10, p.203 de 215, jan/abr.2017 
utiliza todos os meios possíveis para extinguir seus adversários e se tornar o presidente dos Estados Unidos. (IMDB, 2015). A audiência da série é predominantemente jovens e jovens adultos do sexo masculino (CANTER, 2015; PEOPLE PATTERN, 2015).

Em primeira instância, a série foi concebida utilizando um enorme banco de dados, que continha os hábitos de consumo dos usuários do serviço. Com estes dados, a Netflix obteve conhecimento sobre os principais interesses de seus assinantes: dramas políticos, o ator Kevin Spacey e o diretor David Fincher. Após tal descoberta, a empresa decidiu unir esses três fatores em uma mesma história e produzi-la (JUNIOR, 2014).

Outra quebra de paradigmas foi a forma de distribuição dos episódios (JUNIOR, 2014; SUSMAN, 2013). Todos os 13 capítulos foram ofertados ao mesmo tempo, sendo considerado uma inovação no processo de transmissão. Para Junior (2014), essa estratégia foi idealizada devido ao fenômeno conhecido como binge watching, que se refere ao ato de assistir dois ou mais episódios de uma série de uma vez só, como em uma maratona de episódios.

\subsection{PRODUCT PLACEMENT NA NETFLIX - HOUSE OF CARDS}

A grande diferença, com relação à comunicação de marketing, entre a empresa Netflix e as grandes redes mundiais de televisão diz respeito ao não uso de blocos comerciais. Desta forma, a percepção do consumidor é a de acessar conteúdo de entretenimento, sem precisar se submeter à exposição de comerciais. Entretanto, ainda que não apresente os tradicionais blocos comerciais, a Netflix utiliza outro método para chamar a atenção dos anunciantes para as suas produções originais: as marcas podem providenciar a inserção de seus produtos em séries originais da empresa, por meio de Product Placement. (PETERSON, 2015).

Apesar da empresa não se pronunciar oficialmente acerca dos contratos de PP que são realizados, Jim Holleran, diretor de Marketing de Entretenimento da A-B InBev, empresa anunciante na série House Of Cards, aponta sobre como funciona esse tipo de inserção e como a empresa mede seus valores: inicialmente, o PP ocorre por meio de uma leitura preliminar do script, buscando achar uma sinergia entre o show e a marca, observando se esta encontra-se alinhada com o gênero ou com o idealismo do show. Para ele, o sucesso deste tipo de publicidade está na

Rev.Cad. Comun. Santa Maria, v.21, n.1, art 10, p.204 de 215, jan/abr.2017 
correta congruência entre o produto, a cena, o personagem e o episódio (PETERSON, 2015).

O diretor de Marketing afirma que para obter conhecimento sobre o impacto de uma inserção de PP na Netflix é necessário considerar o valor de Marketing associado à este serviço, juntamente com o buzz feito pela indústria de entretenimento acerca da série utilizada. Para ele, o contrato feito foi vantajoso para a marca Stella Artois, tanto com base no volume de vendas, quanto à sua rentabilidade. (PETERSON, 2015) Em suma, associar a marca à Netflix e, principalmente, à série House Of Cards foi algo bastante gratificante para a A-B InBev. Além das marcas desta empresa, é possível salientar outras marcas inseridas na série, como, a Apple, que, de acordo com a Concave Brand Traking (2015), é a que possui maior visibilidade dentro do programa, sendo inserida em boa parte dos episódios.

\section{METODOLOGIA}

O artigo tem como objetivo analisar a contribuição da percepção do PP na atitude dos telespectadores frente às marcas inseridas no seriado norte-americano House Of Cards, exibido pela empresa de entretenimento em streaming Netflix.

Como meio investigativo se fez uso de levantamento bibliográfico e artigos, complementado por um estudo de caso que, de acordo com Yin (2015), investiga um fenômeno contemporâneo, com foco em um caso específico, retendo uma visão holística e do mundo real, como no estudo do comportamento de pequenos grupos.

Aplicou-se questionário semiestruturado com o propósito de analisar a percepção e a atitude de uma amostra de telespectadores, baseada no perfil do público-alvo da série. De acordo com Canter (2015), a maioria da audiência de House Of Cards são pessoas que de alguma forma se enquadram no ramo executivo, mais especificamente, jovens e profissionais do sexo masculino.

A amostra foi escolhida segundo o critério de acessibilidade (por conveniência), de julgamento e de tipicidade. Em conformidade com Vergara (2014) esta é constituída pela seleção de elementos que o pesquisador considere representativos do público-alvo, e aquela pela facilidade de acesso aos mesmos. Com relação ao critério de julgamento considerou-se um mínimo de 7 episódios assistidos pela amostra.

RRev.Cad. Comun. Santa Maria, v.21, n.1, art 10, p.205 de 215, jan/abr.2017 
O questionário foi construído a partir da observação crítica da série em questão, identificando as marcas inseridas sob o formato de PP e a tipificação segundo o tipo de inserção.

O questionário foi estruturado em duas partes, a primeira sobre o perfil dos respondentes e a segunda para identificar a lembrança de marca. Com o intuito de avaliar a percepção no contexto da série, utilizaram-se 3 momentos: (1) lembrança espontânea, (2) lembrança estimulada por categoria, e (3) lembrança estimulada pela marca. Para esta última, realizou-se um levantamento contabilizando 142 marcas distintas inseridas na série House Of Cards, citadas pelas seguintes fontes: Brands\&Films (2013, 2014), Acuna (2015), IMCDB (2016) e Sharkey (2015). Destas 15 foram colocadas no questionário. A seleção das marcas ocorreu pela distribuição em diferentes categorias e pela forte presença e significância delas no contexto brasileiro.

Os questionários foram aplicados por meio de plataforma on-line GoogleDocs junto telespectadores que curtem a página ou fazem parte de grupos da série na rede social Facebook. Ao todo foram realizados 5.832 contatos, destes, foram obtidas 139 respostas, configurando $2 \%$ de retorno. Após a análise dos questionários, foram validados 124 questionários, constituindo a amostra de análise.

Os questionários validados foram exportados para o Excel para uma primeira organização nos dados. Após a conclusão desta fase, foi utilizado o programa SPSS com o objetivo de realizar o cruzamento entre os fatores socioeconômicos e as perguntas referentes ao referencial teórico. Por fim, foi efetuada a análise dos dados, apontando como esta amostra percebeu as inserções de marca apresentadas na série e qual a sua atitude perante este tipo de publicidade.

\section{ANÁLISE DE RESULTADOS}

O perfil da amostra analisada aproxima-se do mencionado por Canter (2015) e People Pattern (2015), ou seja, predominantemente do sexo masculino (71\%), jovens e jovens adultos (70\%). Deve-se considerar também que $89 \%$ têm ensino superior incompleto ou maior grau de instrução e são predominantemente das classes A e B (77\%). Assim, mesmo se tratando de uma amostra não probabilística e por julgamento, cujos resultados não podem ser projetados para a população, atende às necessidades de cará- 
ter exploratório para este estudo.

Em um primeiro momento procurou-se identificar a percepção das marcas no contexto da série objeto deste estudo, nos níveis espontâneo, estimulado pela categoria e estimulado pela marca, gráfico 1, a seguir:

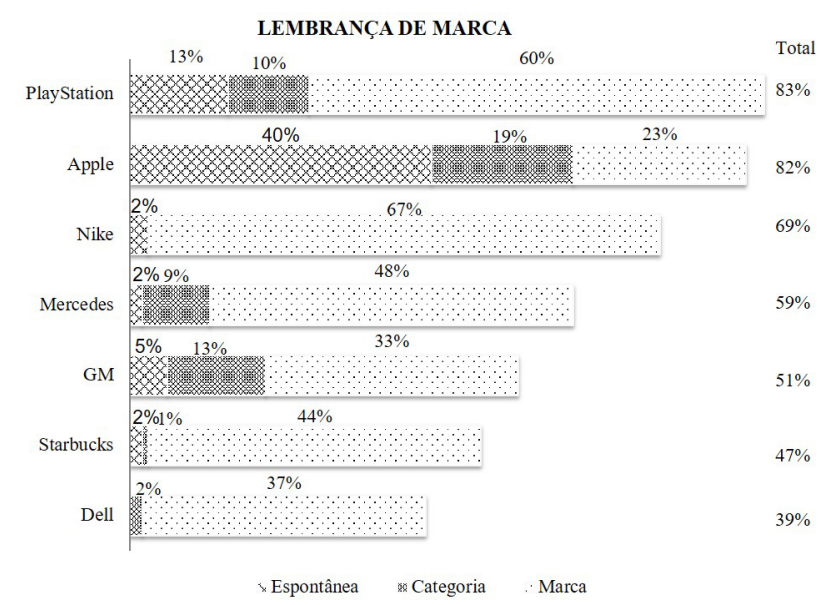

GRÁFICO 1. Marcas mais lembradas pelos entrevistados Fonte: Elaborado pelos autores

Como se observa no gráfico 1, a marca mais lembrada de forma espontânea foi a Apple (40\%), corroborando o exposto na pesquisa da Concave Brand Traking (2015), onde aponta que tal marca possui mais visibilidade do que qualquer outra inserida na série.

A segunda marca mais lembrada de forma espontânea foi a Sony Playstation (13\%). Na fase de observação da pesquisa, ao comparar Apple e Sony PlayStation, percebeu-se que esta não aparece com grande frequência na série, entretanto configura-se como hábitos de lazer do personagem principal, causando dissonância, pois não é comum associar um homem adulto e poderoso com jogos de vídeo game.

Ao estimular a lembrança por categoria, Apple (19\%) e Playstation (10\%) voltam a ser as mais lembradas, seguidas pelas marcas GM (13\%) e Mercedes ( $9 \%$, que fazem parte da categoria de automóveis, utilizadas para a composição dos personagens.

Das 15 marcas apresentadas no questionário com o intuito de estimular a lembrança pela marca, as mais lembradas foram: Nike (67\%), Playstation (60\%), Mercedes (47\%), Starbucks (43\%), Dell (37\%) e Apple (23\%). Ou seja, a maior percepção das marcas pode estar condicionada à forma como elas estão inseridas no conteúdo ofertado, já que as mais lembradas no total são marcas que foram percebidas, por mais de $46 \%$ dos respon-

Rev.Cad. Comun. Santa Maria, v.21, n.1, art 10, p.207 de 215, jan/abr.2017 
dentes, interagindo com os personagens e inseridas de forma coerente no contexto.

Esse resultado vai ao encontro da afirmativa de Lehu (2007), que aponta ser um feito considerável a inserção de PP que consegue facilitar a introdução e a preservação de uma marca na mente dos telespectadores, fazendo contraponto à grande quantidade de marcas a qual o consumidor é exposto diariamente, por diversos meios.

Ao questionar os respondentes sobre possíveis comportamentos decorrentes da inserção de produtos/marcas no contexto da série, a grande maioria concordou que esse tipo de ação provoca atitudes positivas em relação às marcas anunciadas, como pode ser observado no gráfico 2.

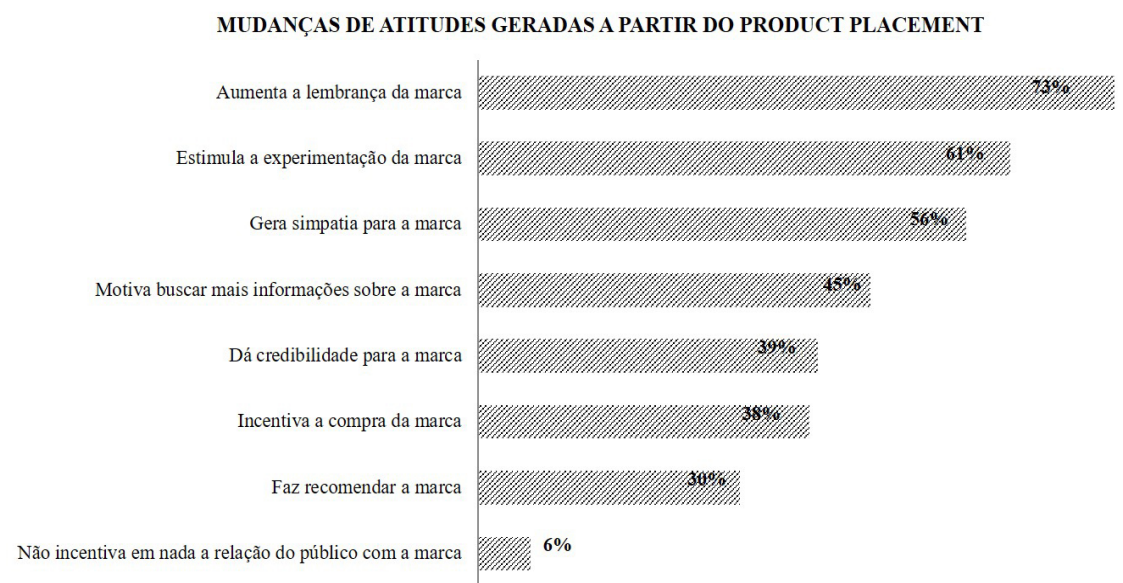

GRÁFICO 2. Mudanças de atitude geradas a partir do PP Fonte: Elaborado pelos autores

No comportamento declarado não há nenhuma variável de análise que se destaque na concordância entre as afirmações, levando a crer que, de uma forma geral, a comunicação via PP provoca atitudes positivas.

Vale ressaltar que apenas $6 \%$ da amostra acredita que esse tipo de inserção "não incentiva em nada a relação do público com a marca", o que pode indicar que esse tipo de comunicação está melhor alinhada com a receptividade do telespectador, não parecendo invasiva. (LEHU, 2007)

Ao questionar se a amostra já comprou/experimentou algum produto e/ou marca que tenha visto em alguma série, $78 \%$ concordaram. O que pode refletir duas situações para esse tipo de publicidade: (1) estimula a compra; (2) reforça positivamente a relação entre a marca e o telespectador, ao se identificar com os personagens da série. Esse resultado concorda com Lehu (2007), quando afirma que, levando em consideração os numerosos casos de sucesso de inserções de PP, é fácil convencer um

Rev.Cad. Comun. Santa Maria, v.21, n.1, art 10, p.208 de 215, jan/abr.2017 
anunciante acerca do potencial de influência que este tipo de publicidade possui no comportamento de consumo de um segmento de mercado.

Afim de identificar qual a atitude provocada pelas diferentes técnicas de Product Placement, utilizou-se uma escala de concordância, dispostas na tabela 1, abaixo.

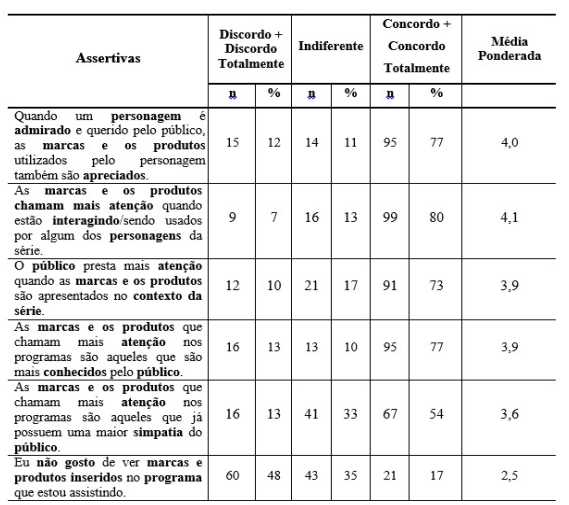

TABELA 1. Grau de concordância com as assertivas

Fonte: Elaborada pelos autores

Com relação à influência dos personagens na inserção de $\mathrm{PP}, 77 \%$ da amostra concorda que quando um personagem é querido, as marcas utilizadas por este personagem também são apreciados. Ainda neste quesito, é possível pontuar que a grande maioria dos respondentes acredita que as marcas chamam mais atenção quando aparecem interagindo com algum personagem ( $80 \%$ ) ou quando são apresentadas no contexto da série (73\%). As inserções da SonyPlaystation em House Of Cards possuem alto grau de congruência com a narrativa (plot placement), utilizam o PP do tipo visual (screen placement), e fazem uso de personagens, apontando seus hábitos de lazer. De acordo com o princípio da identificação, parte do segmento de telespectadores procura produtos vistos em filmes para se parecer ao máximo com aquele personagem admirado, criando a ilusão de seguir os seus passos. (LEHU, 2007).

No cerne acerca do conhecimento e da simpatia de marca, a amostra concorda que aquelas mais conhecidas (77\%) e mais queridas (54\%) pelo público despertam maior atenção. Corroborando com tal análise, as duas marcas mais lembradas pela amostra são bastante conhecidas no mercado nacional e possuem muitos fãs. Lehu (2007) afirma que a familiaridade com a marca, assim como a frequência de consumo, são pontos importantes para a sua memorização.

Analisando a menor média da tabela $(2,5)$ é possível afirmar que boa

Rev.Cad. Comun. Santa Maria, v.21, n.1, art 10, p.209 de 215, jan/abr.2017 
parte da amostra não se incomoda de ver marcas inseridas em um determinado programa, mostrando-se aberta para este tipo de inserção. A grande maioria dos estudos realizados sobre o assunto confirmam uma tolerância geral entre o público e a colocação de produtos sob formato de PP, e, em casos de integração bem sucedida, até mesmo uma apreciação desta abordagem. (LEHU, 2007).

Em suma, diante dos dados coletados, é perceptível a importância do uso do Product Placement como técnica eficiente para veiculação de marcas. Esse fenômeno é percebido sobretudo quando $73 \%$ dos respondentes concorda que tal ação aumenta a lembrança da marca, ilustrando-a como instrumento de efeito marcante na mente destes, além de estimular a experimentação (61\%) e, até mesmo, incentivar a compra da marca (38\%).

Das formas de inserção, pode-se inferir, pelo resultado desse estudo, que o PP mais efetivo é o do tipo clássico, visual (screen placement) e cuja marca/produto aparece em concordância com o contexto apresentado, integrados na narrativa (plot placement) e interagindo com os personagens da cena.

\section{CONSIDERAÇÕES FINAIS}

Em um comparativo entre as duas marcas mais lembradas, Apple e Sony PlayStation, é perceptível que aquela faz uso de inserções proeminentes, dentro de um contexto adequado, em concordância com o perfil dos personagens, e inserindo seus produtos de forma persistente na série, causando uma retenção por repetição na memória dos telespectadores. Já as inserções da Sony PlayStation surgem como uma dissonância entre os hábitos de lazer do personagem principal e a sua personalidade, surpreendendo os telespectadores, pois normalmente, esta marca é associada à jovens e crianças. Este ruído remete ao fato de que a utilização de PP, em situações inusitadas, pode gerar uma maior lembrança, quando comparada as inserções de marcas em um contexto já esperado pelos telespectadores.

Outro ponto a ser observado acerca da lembrança de marca é o referente aos produtos inseridos na categoria de alimentos. Estes foram os menos lembrados pela amostra, e, na série, estão normalmente inseridos como Product Placement corporativo, com foco na marca ao invés do produto, e de proeminência sutil, levando a supor que este tipo de combina- 
ção possa fazer com que o PP passe despercebido.

A partir dos resultados deste estudo exploratório é possível formular as seguintes hipóteses: H1: Utilizar o PP em condições não habituais, ou seja, destoando daquilo que o telespectador espera, chama mais atenção do que quando este se encontra inserido de forma corriqueira; $\mathrm{H} 2$ : A combinação entre o uso proeminente de uma marca, inserida de forma congruente com o contexto apresentado, e a utilização de personagens gera retenção desta na memória dos telespectadores; H3: A combinação entre o PP do tipo corporativo com uma proeminência sutil pode levar a uma inserção não eficiente; H4: O PP, diferente de outras formas de publicidade, não apresenta resistência entre a maioria dos telespectadores.

O resultado desta pesquisa permite inferir, a partir da amostra analisada, a capacidade de geração de atitudes positivas, seja fortalecendo a imagem da marca na lembrança, seja despertando a vontade de experimentação desta, contribuindo, assim, para o estreitamento das relações entre o segmento alvo e a marca, e reduzindo seu nível de rejeição, fenômeno mais presente em campanhas publicitárias tradicionais. 


\section{REFERÊNCIAS}

ACUNA, Kirsten. All the brands that appear in 'House of Cards' season 3, 2015. Disponível em: <http://www.businessinsider.com.au/house-of-cards-season-3-brands-2015-3>. Acesso em: 20 jun 2015.

ANDRIASOVA, A. They placed, I saw, I was conquered: evaluating the effects of persuasion knowledge and prominence of brand placement on viewers' attitudes and behavior. University of Texas at Austin, Austin, Texas, EUA, 2006.

BRANDS\&FILMS. Product placement slideshow: House of Cards, 2013. Disponível em: <http://brandsandfilms.com/2013/04/product-placement-slideshow-house-of-cards/>. Acesso em: 20 jun 2015.

BRANDS\&FILMS. Product placement slideshow: House of Cards, 2014. Disponível em: < http://brandsandfilms.com/2014/02/product-placement-slideshow-house-of-cards-2/>. Acesso em: 20 jun 2015.

CANTER, Leslie. Audience Insights Drive Product Placement in House of Cards, 2015, People Pattern. Disponível em: < https://www.peoplepattern.com/big-data-drives-product-placement-house-cards/>. Acesso em: 20 fev 2016.

COBRA, M. H. N. (Org.). Marketing do Entretenimento. São Paulo: Editora Senac, 2008.

CONCAVE BRAND TRACKING. Apple still \#1 Brand In House Of Cards' 3rd Season, 2015. Disponível em: < http://concavebt.com/apple-still-number-1-brand-house-cards-3rd-season/>. Acesso em: 20 fev 2016.

ETZEL, M. J.; WALKER, B. J.; STANTON, W. J. Marketing. São Paulo: Makron Books, 2001.

HAWKINS, D. I.; MOTHERSBAUGH, D. L.; BEST, R. J. Comportamento do consumidor: construindo a estratégia de marketing. Rio de Janeiro: Elsevier, 2007.

IMCDB, 2016. Disponível em: <http://www.imcdb.org/movie_1856010-House-of-Cards. html>. Acesso em: 20 jun 2015.

IMDB. House Of Cards, 2016. Disponível em: < http://www.imdb.com/title/ tt1856010/?ref_=ttawd_awd_tt >. Acesso em: 12 out 2015.

JENKINS, Henry. Cultura da Convergência. São Paulo: Aleph, 2009

Rev.Cad. Comun. Santa Maria, v.21, n.1, art 10, p.212 de 215, jan/abr.2017 
JUNIOR, Eliseu Bezerra. Porque todos querem ser a Netflix, 2014. Disponível em: < http://exame.abril.com.br/rede-de-blogs/digitos/2014/04/28/por-que-todos-querem-ser-a-netflix/>. Acesso em: 20 março 2015.

KATZ, Daniel. The functional approach to the study of attitudes. Public Opinion, v. 24, dec. 1960, p. 163-204.

KEATING, Gina. Netflixed: The Epic Battle for America's Eyeballs. 1ed. EUA: Editora Pearson, 2013.

KOTLER, P.; ARMSTRONG, G. Princípios de Marketing. 12. ed. São Paulo: Editora Pearson, 2007.

KOTLER, Philip; KELLER, Kevin. Administração de Marketing. 14. ed. São Paulo: Pearson Prentice Hall, 2012.

LAWALL, Thais Mendes. 0 product placement no cinema brasileiro: Um estudo de caso do filme Divã. Universidade Federal De Juiz De Fora, Juiz de Fora, Brasil, 2013.

LEE, M.; FABER, R.J. Effects of Product Placement in On-line Games on Brand Memory: A perspective of the limited-capacity model of attention. Journal Of Advertising, EUA, v.36, n. 4, p. 75-90, 2007.

LEHU, Jean Marc. Branded Entertainment: Product placement \& brand strategy in the entertainment business. Londres: KoganPage, 2007.

LINDSTROM, Martin. Lógica do Consumo: verdades e mentiras sobre por que compramos. São Paulo: Nova Fronteira, 2009.

MOWEN, John C.; MINOR, Michael S. Consumer Behavior: a framework. United States of America: Prentice-Hall, 2001.

NETFLIX MEDIA CENTER. Netflix Timeline, 2016. Disponível em: < https://media.netflix. com/en/about-netflix>. Acesso em: 12 dez 2015.

NEWELL, J., SALMON, C., \& CHANG, S. The Hidden History of Product Placement. Journal of Broadcasting \& Electronic Media, v. 50, n. 4, p. 575-594, 2006.

PEOPLE PATTERN, 2015. Disponível em: <http://www.peoplepattern.com/wp-content/ uploads/2015/03/Screen-Shot-2015-03-04-at-8.35.05-AM.png>. Acesso em: 20 fev 2016.

PETERSON, Tim. Netflix Isn't Closed to Advertisers After All; Just Ask Anheuser-Busch InBev. AdvertisingAge, 2015. Disponível em: <http://adage.com/article/media/netflix-s-house-cards-tout-anheuser-busch-samsung/297318/>. Acesso em: 20 abril 2015.

Rev.Cad. Comun. Santa Maria, v.21, n.1, art 10, p.213 de 215, jan/abr.2017 
PINHEIRO, Roberto M. et al. Comportamento do Consumidor e pesquisa de mercado. 3.ed. Rio de Janeiro, Editora FGV, 2006.

ROBBINS, Stephen P. Comportamento organizacional. 11. ed. São Paulo, SP: Prentice Hall, 2005

SARAIVA JUNIOR, Francisco Ilson. Segmentação de mercados. In: Marcos Cobra. (Org.). Marketing do Entretenimento. São Paulo: SENAC, 2008, v.1 , p. 261-273.

SHARKEY, Linda. House of Cards: The impeccable style of Claire Underwood, 2015. Disponível em: <http://www.independent.co.uk/life-style/fashion/features/house-of-cards-the-impeccable-style-of-claire-underwood-10076144.html> Acesso em: 20 jun 2015.

SUSMAN, Gary. O futuro dos filmes: a Netflix se tornará o próximo grande estúdio de Hollywood?, 2013. Rolling Stones. Disponível em: <http://rollingstone.uol.com.br/noticia/o-futuro-dos-filmes-netflix-se-tornara-o-proximo-grande-estudio-de-hollywood/>. Acesso em: 15 nov 2015

TAMANAHA, Paulo. Planejamento de mídia. Teoria e experiência. São Paulo: Pearson Prentice Hall, 2006.

URDAN, André Torres; URDAN, Flávio Torres. Marketing estratégico no Brasil: teoria e aplicações. São Paulo: Atlas, 2010.

VERGARA, Sylvia Constant. Projetos e relatórios de pesquisa em administração. 15 . ed. São Paulo: Atlas, 2014.

VOGELSTEIN, F. Briga de cachorro grande. Rio de Janeiro: Intrínseca, 2014.

WALLENSTEIN, Andrew. Netflix Ratings Revealed: New Data Sheds Light on Original Series' Audience Levels, 2015. Disponível em: <http://variety.com/2015/digital/news/ netflix-originals-viewer-data-1201480234/>. Acesso em: 20 jun 2015.

YIN, Robert K. Estudo de Caso: Planejamento e Métodos. 5. Ed. Porto Alegre: Bookman, 2015 


\section{Nicolas Marques Paiva}

Graduado em Comunicação Social - Publicidade e Propaganda pela Universidade de Fortaleza (2012). Graduando em Administração de Empresas pela Universidade Federal do Ceará. Bolsista do Programa de Educação Tutorial do Curso de Administração.

E-mail:nicolasmpaiva@gmail.com 